Article

\title{
Monitoring Earthquake-Damaged Vegetation after the 2008 Wenchuan Earthquake in the Mountainous River Basins, Dujiangyan County
}

\author{
Huaizhen Zhang ${ }^{1,2,3}$, Xiaomeng Wang ${ }^{2,3, \dagger}$, Jianrong Fan ${ }^{1, *}$, Tianhe Chi $^{2, \dagger}$, Shun Yang ${ }^{4, \dagger}$ \\ and Ling Peng $2, \dagger$
}

1 Institute of Mountain Hazards and Environment, Chinese Academy of Sciences, Chengdu 610041, China; E-Mail: zhanghz@radi.ac.cn

2 Institute of Remote Sensing and Digital Earth, Chinese Academy of Sciences, Beijing 100101, China; E-Mails: wangxm01@radi.ac.cn (X.W.); chith@radi.ac.cn (T.C.); PL20158@126.com (L.P.)

3 University of Chinese Academy of Sciences, Chinese Academy of Sciences, Beijing 100049, China

4 Technical Center for Geological Hazard Prevention and Control, Chinese Geological Survey, Chengdu 611734, China; E-Mail: yangsh@cgiet.com

† These authors contributed equally to this work.

* Author to whom correspondence should be addressed; E-Mail: fjrong@imde.ac.cn; Tel./Fax: +86-28-8501-8812.

Academic Editors: Richard Gloaguen and Prasad S. Thenkabail

Received: 26 March 2015 / Accepted: 18 May 2015 / Published: 28 May 2015

\begin{abstract}
The 2008 Wenchuan earthquake destroyed large areas of vegetation in the Baisha River and Longxi River basins, in Dujiangyan County, China. There were several debris flow events in these mountainous river basins after 2008. Currently, these damaged vegetation areas are in various stages of recovery. This recovery vegetation improves the resistance of slopes to both surficial erosion and mass wasting. We introduce a probabilistic approach to determining the relationships between damaged vegetation and slope materials' stability, and model the sediment and flow (hydrological) connectivity index to detect the hydrological changes in a given river basin, using the multi-temporal (1994-2014) remote-sensing images to monitor the vegetation recovery processes. Our results demonstrated that the earthquake-damaged vegetation areas have coupling relationships with topographic environment and slope material properties, and can be used to assess the slope material stability. Further, our analysis results showed that the areas with horizontal distance to river
\end{abstract}


streams $<500 \mathrm{~m}$ are areas that actively contribute sediment to the stream channel network, and are main material sources for debris flow processes in one given mountainous basin.

Keywords: earthquake; vegetation recovery; remote sensing; hydrological connectivity

\section{Introduction}

The 2008 Wenchuan Earthquake with its strong ground motion triggered a great number of landslides [1-5] that caused large areas of vegetation destruction in the vegetation-covered mountain areas. Data from the forestry department of Sichuan Province, China showed that forest land deteriorated by $32.867 \times 10^{4}$ ha, with a direct economic loss of the forest system estimated to be as much as 23 billion RMB [6]. Most of the damaged vegetation was distributed along both sides of the river, causing erosion and formation of debris flows [2,7]. Currently, the areas of damaged vegetation are at various stages of recovery, and some fully recovered within only a few years of the earthquake. These recovered vegetation areas improve the resistance of slopes to both surficial erosion and mass wasting. Nevertheless, the potential for future slope instability still exists.

Most existing studies have focused on the earthquake-induced geo-hazards and environmental changes in the Wenchuan earthquake-affected region [3-5,8-11]. Only a few studies have reported vegetation recovery after the earthquake. Liu et al. monitored the early vegetation recovery within two months of the earthquake using MODIS GPP time-series products [12]. Lu et al. (2012) used a time series of Landsat TM imagery to quantitatively assess the vegetation damage and monitor the vegetation recovery process after the earthquake and its associated secondary disasters [13]. Jiao et al. assessed the spatiotemporal variations in vegetation recovery after the earthquake using the Normalized Difference Vegetation Index (NDVI) based on the Landsat images [14]. Zhang et al. documented the natural recovery of forests after the earthquake and revealed that factors including soil cover and slope were correlated with successful vegetation recovery [15]. Li et al. monitored geologic hazards and vegetation recovery in the earthquake-affected region using aerial photography, and found that the intensity and frequency of debris flows gradually decreased with the source material becoming less available and the slope structure stabilizing [16]. In general, damaged vegetation recovery is generally a long-term biological process, and the recovered vegetation also recovers the ecological and hydrological functions.

Many studies have assessed and monitored vegetation recovery in other earthquake regions [17-27]. For example, studies focused on the 1999 Chi-Chi earthquake in central Taiwan found that the vegetation was recovering; in particular, the vegetation restoration rate, two years after the earthquake, was high [27,28], and they documented that soil moisture is one of the most important environmental factors affecting vegetation recovery in the landslide sites in the Jou-Jou Mountain area, Taiwan [17,27]. In addition, Shieh et al. found that the rainfall threshold for debris flow was remarkably lower just after the Chi-Chi Earthquake, but gradually recovered [29].

In the Wenchuan earthquake-hit region, the Baisha River and Longxi River were selected to detect the sediment and flow connectivity changes after the earthquake, through monitoring the recovery processes of the earthquake-damaged vegetation areas. The objectives of this work were to: (1) detect 
the damaged vegetation during the earthquake and monitor the vegetation recovery processes in one given river basin; (2) quantify the slope material stability using the earthquake-damaged vegetation and its survival environments data; and (3) model the sediment and flow connectivity index (SFCI) and its changing processes to detect the main material sources for the debris flow processes.

\section{Study Area}

\subsection{Location}

The study area is located in the north part of Dujiangyan County, Sichuan Province, China, and is approximately $15 \mathrm{~km}$ northeast of the Wenchuan earthquake epicenter (Figure 1a). The earthquake generated high levels of ground shaking (seismic intensity X-XI) in the study area, which included two river basins: Baisha River $\left(354.8 \mathrm{~km}^{2}\right)$ and Longxi River $\left(79.0 \mathrm{~km}^{2}\right)$. Since the study area is situated in the transitional mountainous belt between the Sichuan basin and the western Sichuan Plateau, both river basins are characterized by rugged mountains with deeply incised valleys (Figure 1b). The Longmenshan thrust belt, which ruptured during the Wenchuan earthquake [1-4], runs through the southern part of the study area (Figure 1c). Active geotactic movements induced by the complicated faults system occur frequently in this region. The rocks of the river basins primarily consist of Carboniferous limestone and marlstone (C); Devonian limestone (D); Permian sandstone and shale (P); Proterozoic graphite-schist and quartzite $(\mathrm{Pt})$; Quaternary deposits $(\mathrm{Q})$; Triassic sandstone $(\mathrm{T})$; Sinian sandstone and siltstone (Z); Proterozoic diorite (R1); Proterozoic K-feldspar granite (R2); Proterozoic plagioclase granite (R3); and Proterozoic biotite granite (R4).

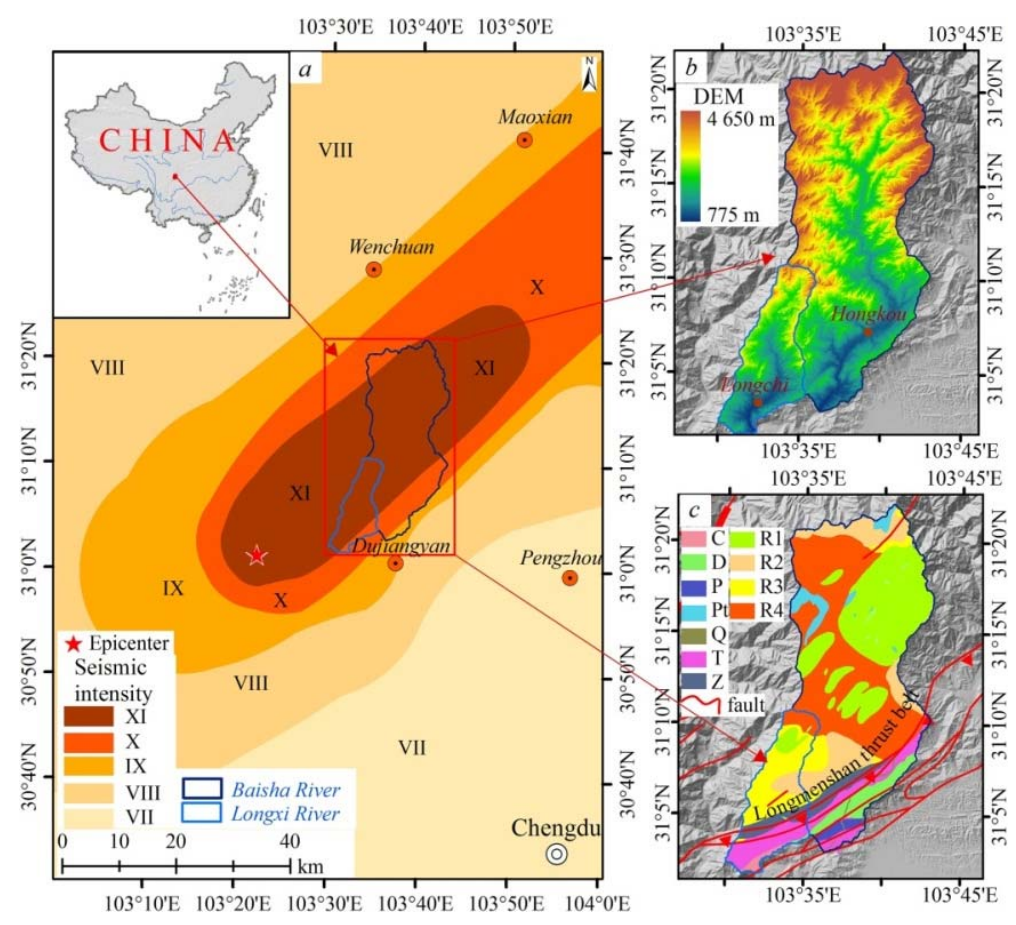

Figure 1. (a) Study area and Wenchuan earthquake seismic intensity map; (b) digital Elevation Models (DEM) map of the study area; (c) simplified geological map of the study area. 


\subsection{Pre-Earthquake and Post-Earthquake Vegetation in Study Area}

The study area is influenced by a subtropical moist climate and monsoonal rains that start in early May and continue until September. The average rainfall in the region is approximately $1134 \mathrm{~mm}$, of which about $80 \%$ is monsoonal; the mean annual temperature is about $15.2{ }^{\circ} \mathrm{C}$ (www.weather.com.cn). As a result of this variable climate, the area was rich with vegetation before the Wenchuan earthquake (Figure $2 \mathrm{a}-\mathrm{c}$ ). The main vegetation types include evergreen broadleaf forest, evergreen coniferous forest, deciduous broadleaf forest, shrubs, and meadows.

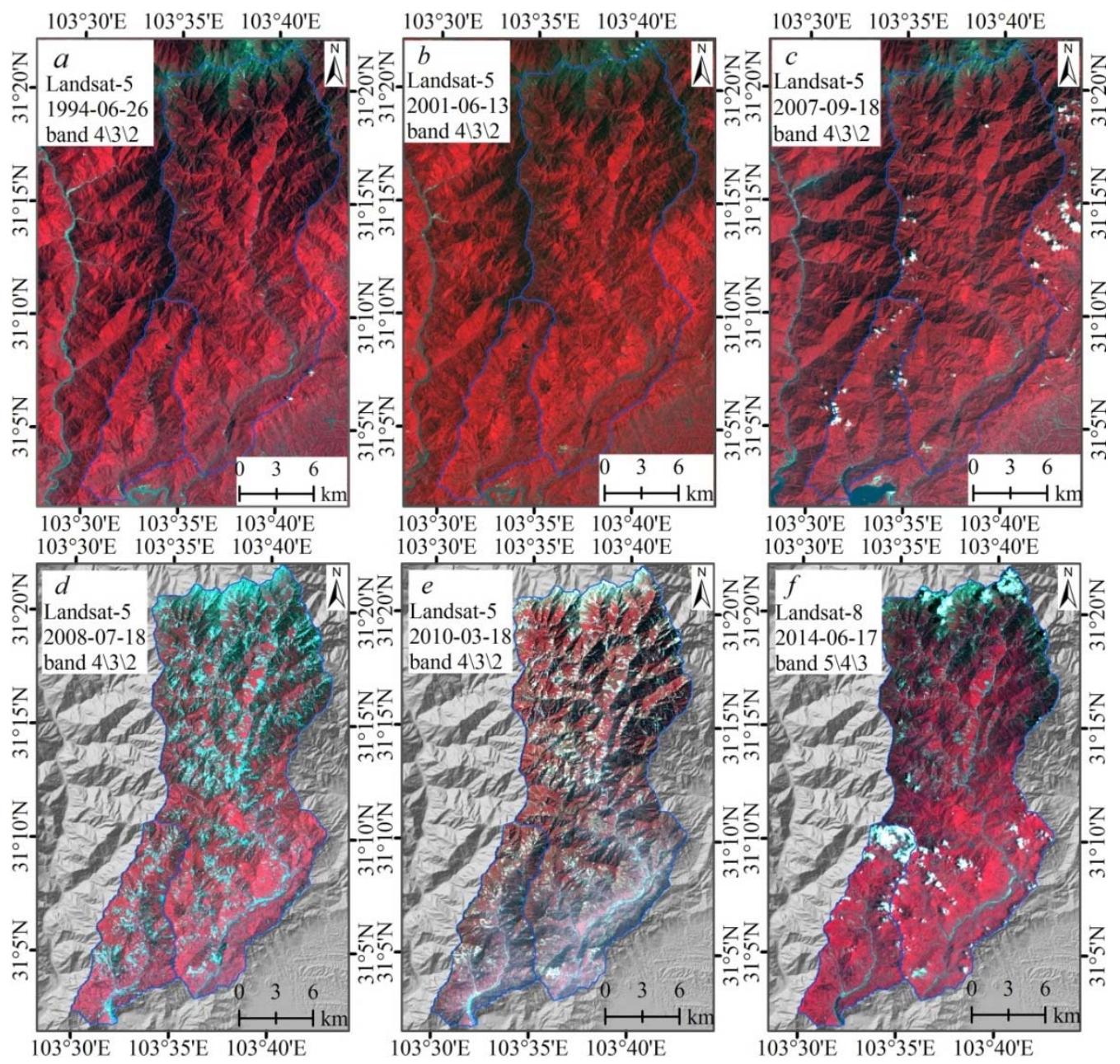

Figure 2. Multi-temporal Landsat-5/8 images at the study area (a) 26 June 1994 Landsat-5 image; (b) 13 June 2001 Landsat-5 image; (c) 18 September 2007Landsat-5 image; (d) 18 July 2008Landsat-5 image; (e) 18 March 2010Landsat-5 image; (f) 17 June 2014 Landsat-8 image.

Within the study area, geo-hazards induced by the 2008 Wenchuan earthquake resulted in massive movement of the surface material, which diminished and destroyed large areas of vegetation (Figure 2d). Since the earthquake, the damaged vegetation has been recovering (Figure 2e). The Landsat- 8 image of the study area (Figure 2f) shows that most of the damaged vegetation has recovered, while some areas have not. For example, Figure 3 shows the pre- and post-earthquake vegetation in the 
Guoquanyan gully, where it can be seen that the shrubs and meadows began to recover in some of the damaged areas first.
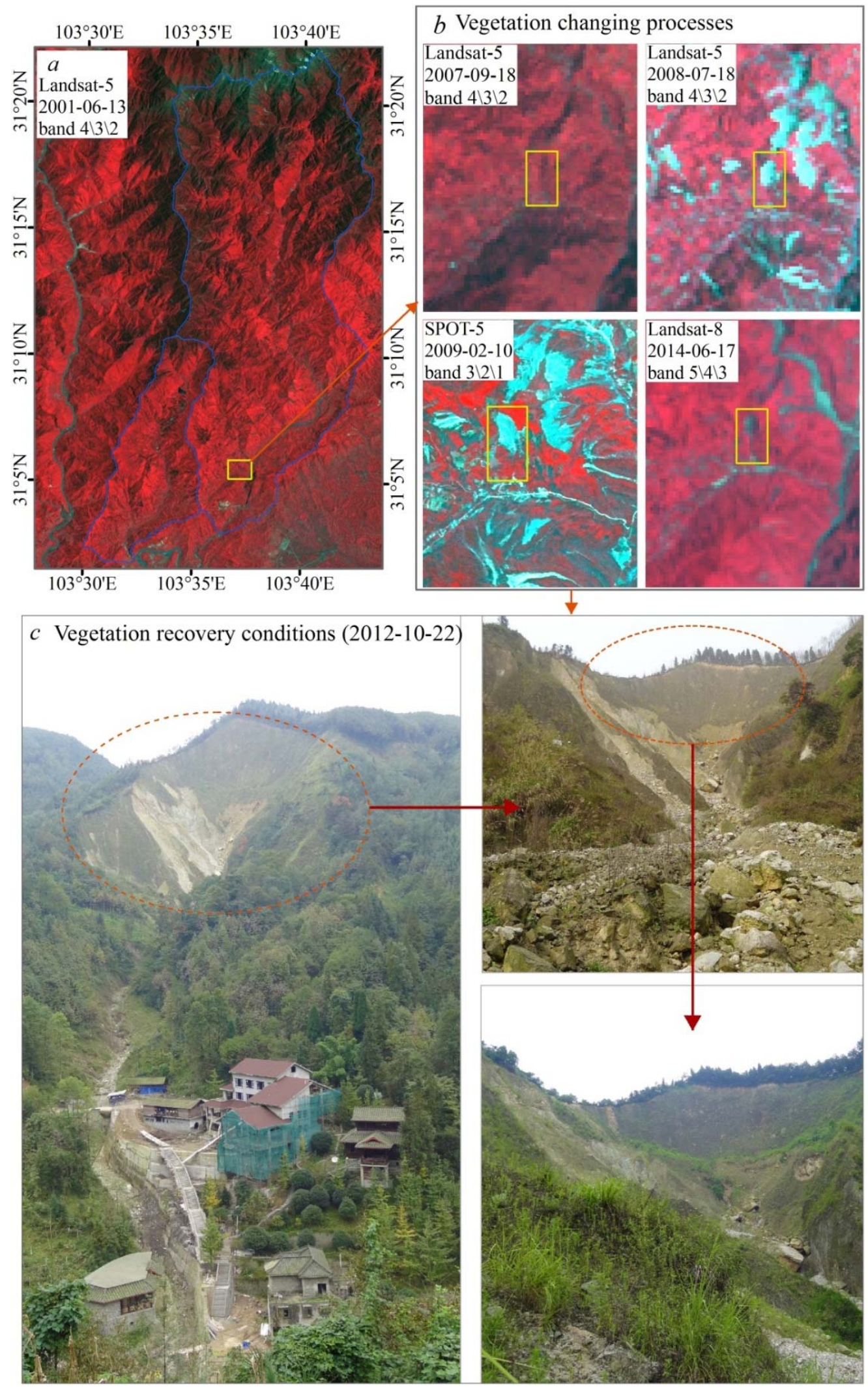

Figure 3. Pre- and post-earthquake vegetation in the Guoquanyan gully: (a) Guoquanyan gully location; (b) vegetation changing processes; (c) vegetation recovery conditions. 
These areas of damaged vegetation and the recovery processes can be detected by examining changes in the normalized difference vegetation index (NDVI) values, which are derived from both the red and near-infrared spectral bands and are sensitive to changes in biophysical conditions of vegetation [24,30-32]. The results indicated that there were high NDVI values in most areas of the study area (Figure 4a), obvious changes in the NDVI were observed after the earthquake (Figure 4b), and the damaged vegetation had been recovering since the earthquake (Figure 4c).

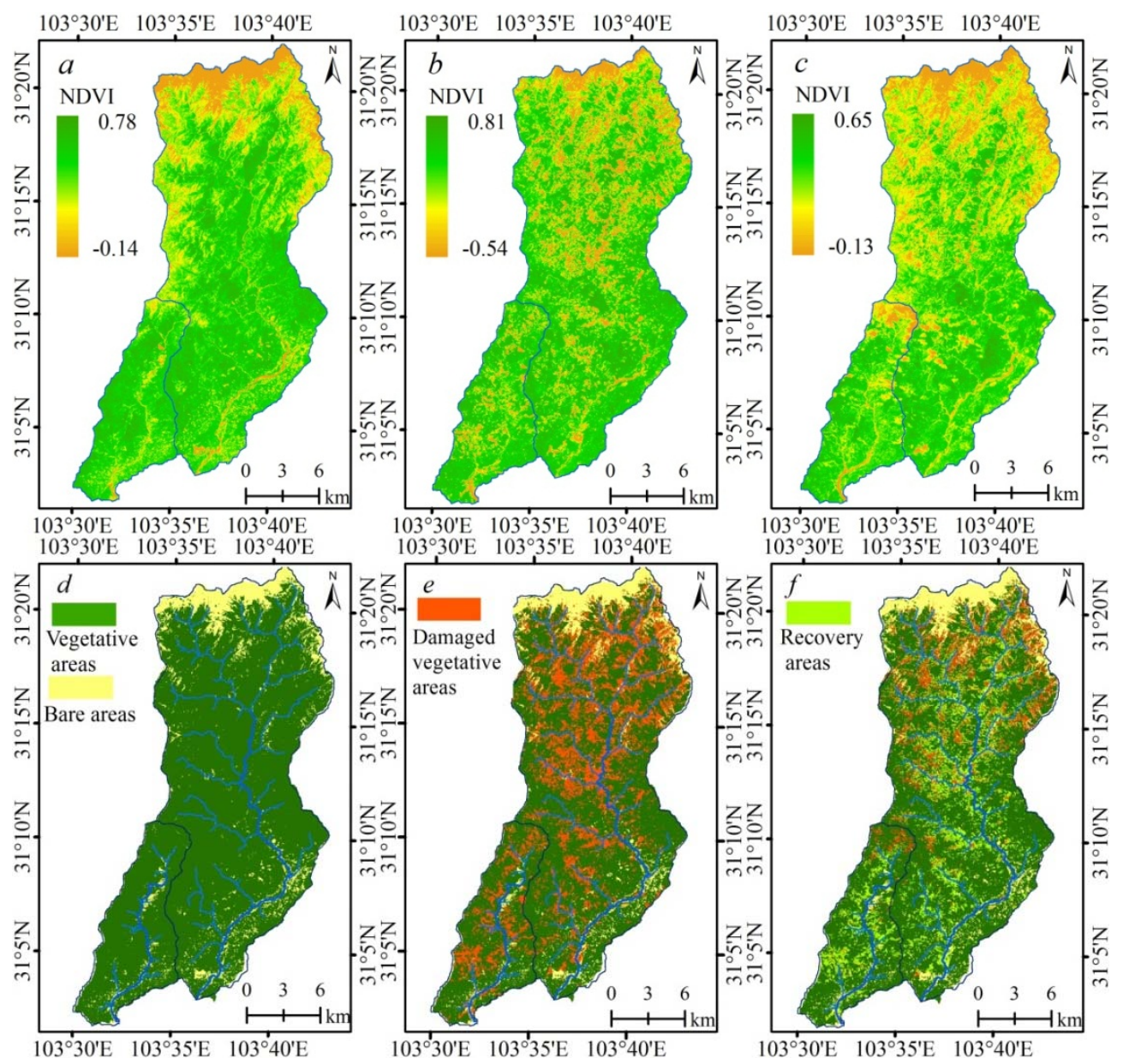

Figure 4. Multi-temporal NDVI images and vegetation changes processes at the study area: (a) Pre-earthquake NDVI image; (b) 2008-2009 NDVI image; (c) 2014 NDVI image; (d) pre-earthquake vegetation distribution map; (e) earthquake-damaged vegetation distribution map; (f) vegetation recovery conditions map.

Using the NDVI maps, the study area was divided into vegetative (NDVI $\geq 0.15$ ) and bare (NDVI < 0.15) areas (Figure 4d) based on the pre-earthquake NDVI image. These areas of damage after the earthquake were distributed along the stream network of the basin (Figure 4e), and were at various stages of recovery since the earthquake (Figure 4f).

Statistical analysis showed that the total size of the damaged area was about $102.7 \mathrm{~km}^{2}(28.9 \%$ of the total river area) in the Baisha River basin, and the damaged area was about $19.3 \mathrm{~km}^{2}(24.4 \%$ of the total river area) in the Longxi River basin, while the recovered area was about $59.3 \mathrm{~km}^{2}(57.7 \%$ of the total damaged areas) in the Baisha River basin, and the recovered area was about $14.8 \mathrm{~km}^{2}(76.7 \%$ of the total damaged areas) in the Longxi River basin. 


\section{Data Analysis}

\subsection{Vegetation Survival Environments in Mountain Basins}

Vegetation growth and distribution depend primarily on environmental factors, such as sunshine, water, temperature (heat energy), and nutrients. Furthermore, these inputs have direct relationships with environmental conditions. For example, topography influences the vegetation growing environment in a variety of ways, including through elevation effects on temperature, slope aspect controls on sunshine, and slope effects on hydrological conditions. Moreover, the geological setting (particularly lithology) affected the soil properties and stream conditions.

River basins represent natural hydrological units for which it is possible to determine balances between the major constituent fluxes of rainfall, evaporation, river discharge, and groundwater storage [33]. Additionally, river basins are a natural result of changes in geomorphic processes. Hence, river basins can be characterized by their natural features, in particular in terms of topographical and stream conditions. Further, at the basin scale, the vegetation survival environment can be characterized by topography, stream systems, and lithology conditions.

To determine the key features of the vegetation survival environment in the Baisha River and Longxi River basins, digital elevation models (DEM) data (resolution: 10m) were produced from a 1: 10,000 standard topographic map (Figure 1b), and the slope gradient (Figure 5a) and slope aspect (Figure 5b) were calculated. Then, the river streams were extracted with the accumulated threshold value $1.0 \mathrm{~km}^{2}$ using the TauDEM toolbox in ArcGIS 9.3 platform, and the vertical drop to river streams $V_{d}$ (Figure 5c) and horizontal distance to river streams, $H_{d}$ (Figure 5d), were calculated.

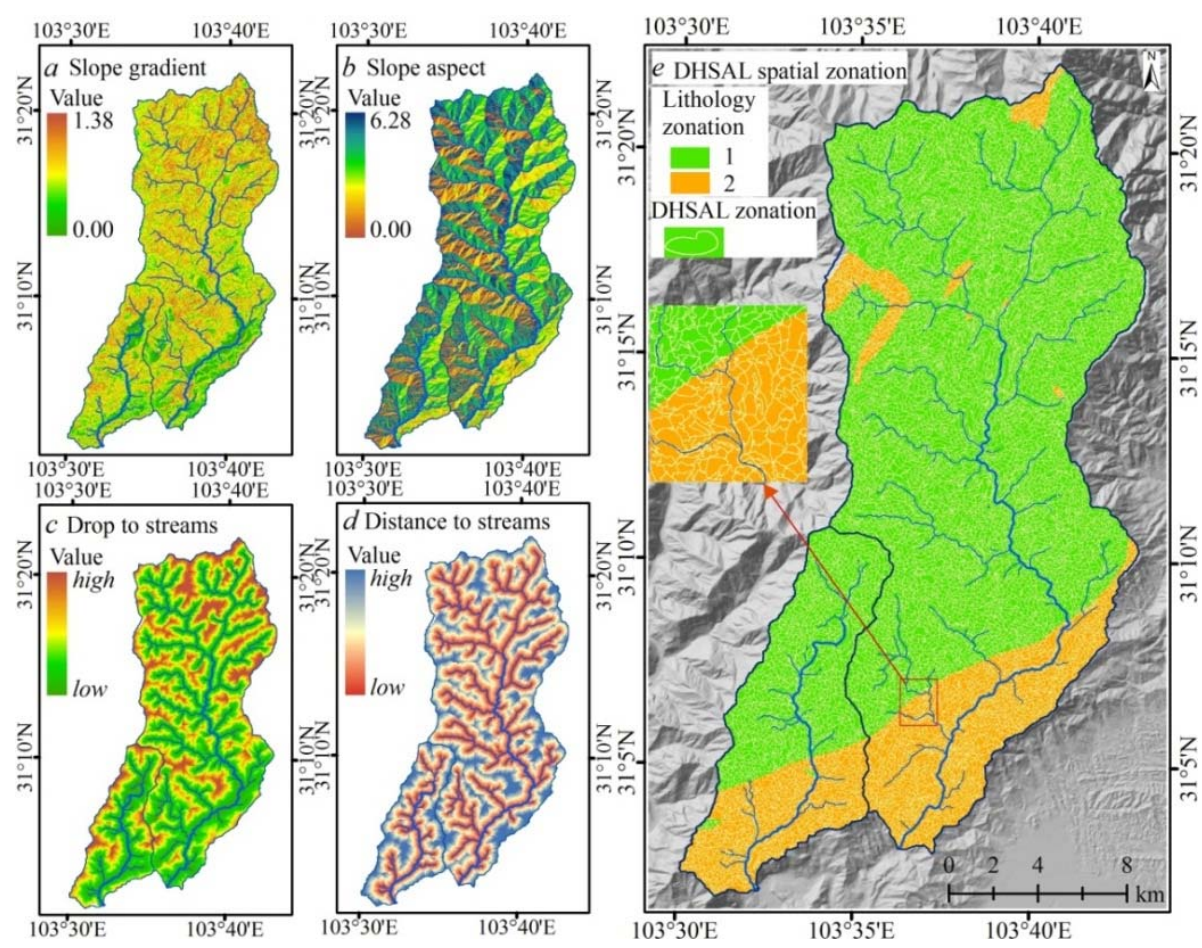

Figure 5. (a) Slope gradient map of the study area; (b) slope aspect map of the study area; (c) drop to the streams map of the study area; (d) distance to streams map of the study area; (e) DHSAL spatial zonation map of the study area. 
Statistical results indicate that the DEM and slope gradient values show normal distribution features, and the slope aspect shows uniform features. Furthermore, the $V_{d}$ values have strong correlations with the DEM values, and the areas with $H_{d}<1600 \mathrm{~m}$ were dominant in this region (i.e., $96.9 \%$ of the Baisha River basin, and $94.9 \%$ of the Longxi River basin).

Based on these natural features, the DEM and slope gradient data were mapped into four classes (i.e., 1: $<\mu-\sigma, 2:[\mu-\sigma, \sigma), 3:[\mu, \mu+\sigma], 4:>\mu+\sigma)$ using the mean $(\mu)$ and standard deviation $(\sigma)$ values. The slope aspect was also divided into four classes (i.e., 1: $\left[45^{\circ}, 135^{\circ}\right], 2$ : $\left[135^{\circ}, 225^{\circ}\right], 3$ : $\left[225^{\circ}, 315^{\circ}\right], 4:\left[315^{\circ}, 360^{\circ}\right]$, and $\left[0^{\circ}, 45^{\circ}\right]$ ) based on the direction of sunshine [34]. Furthermore, the $H_{d}$ value was selected to analyze the river stream conditions and was mapped into nine classes $(\mathbf{1}:<200$, 2: [200, 400), 3: [400, 600), .. . , 8: [1 400, 1 600], 9: > 1 600). The lithology units can also be divided into rock competence classes based on their lithological and structural properties. The lithology units in this region can be divided into two classes (i.e., 1: granite rocks, 2: No-granite rocks). Therefore, one DHSAL (DEM, Horizontal distance to river, Slope gradient, Aspect, and Lithology conditions) spatial zonation was defined as one spatial zonation for one given river basin, based on the natural features of the DEM, horizontal distance to river $H$, slope gradient $S$, slope aspect $A$, and lithology conditions.

The DHSAL spatial zonation results (Figure 5e) showed that there were 488 DHSAL classes with 9470 DHSAL regions in the Baisha River basin and 323 DHSAL classes with 2154 DHSAL regions in the Longxi River basin. Statistical analysis showed that approximately $90 \%$ of the DHSAL regions had internal reliefs ranging from 5 to $200 \mathrm{~m}$, approximately $85 \%$ of the DHSAL regions had slope gradient changes within $10^{\circ}$, and approximately $81 \%$ of the DHSAL regions had horizontal distance to river changes within $100 \mathrm{~m}$. Hence, similar conditions (e.g., elevation, horizontal distance to river, slope gradient, slope aspect, and lithology) existed in each DHSAL region.

To validate the fact that each HSAL region can represent one kind of (vegetation) survival environment, the pre-earthquake NDVI image was selected to detect the vegetation features in each DHSAL region. The results showed that there are strong correlations between vegetation growth and the associated topographical and lithology conditions. These relationships can be expressed as:

$$
V=\alpha \cos (S)+\beta D+\kappa R_{h}\left|\sin \left(\frac{A}{2}-\frac{\pi}{4}\right)\right|, \quad l=i
$$

where $V$ is the mean of NDVI values in each of the DHSAL regions, $\alpha, \beta, \kappa$, and $i$ are the parameters of function (Table 1), which was calculated using the stepwise multiple regression method, $S$ is the mean slope gradient in each of the DHSAL regions $\left(^{\circ}\right), D$ is the ratio of the mean height of the contour above the base (basin mouth) to the total height of the basin, $R_{h}$ is the ratio of the mean $H_{d}$ values to the maximum $H_{d}$ value of the basin, $A$ is the mean slope aspect in each of the DHSAL regions $\left(^{\circ}\right)$, and $l$ is the code for the lithological zonation.

Table 1. Parameters of Equation (1) $n$ the river basins.

\begin{tabular}{cccccc}
\hline River basin & $\alpha$ & $\beta$ & $\kappa$ & $\boldsymbol{i}$ & $\boldsymbol{R}^{2}$ \\
\hline Baisha & 0.816 & -0.307 & 0.053 & 1 & 0.874 \\
Baisha & 0.745 & -0.208 & 0.015 & 2 & 0.835 \\
Longxi & 0.590 & 0.314 & 0.097 & 1 & 0.854 \\
Longxi & 0.600 & 0.282 & 0.181 & 2 & 0.792 \\
\hline
\end{tabular}




\subsection{Vegetation Damaged during the Earthquake and Its Recovery Conditions after}

To determine the relationships between damaged vegetation and survival environment, the vegetation damaged probability $(V D P)$ was defined as the ratio of damaged vegetation areas to total area in each of the DHSAL regions. In addition, to determine the recovery capacity of damaged vegetation, the vegetation recovery probability $(V R P)$ was defined as the ratio of recovered vegetation area to total damaged vegetation area in each of the DHSAL regions. Here, the VDP and VRP of the Baisha River and Longxi River basins were calculated and mapped as shown in Figure 6.

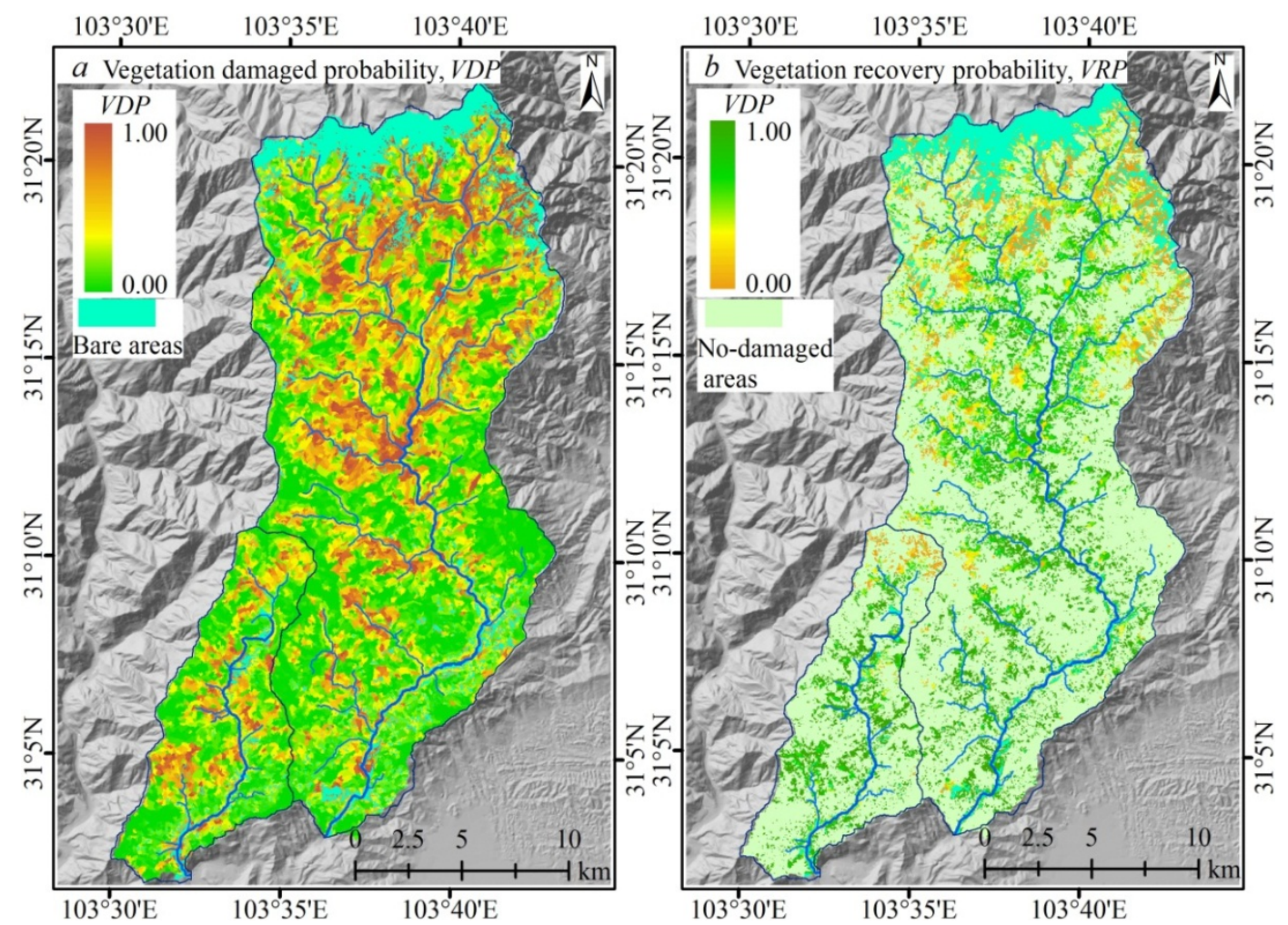

Figure 6. (a) Vegetation damaged probability, VDP map of the study area; (b) vegetation recovery probability, $V R P$ map of the study area.

Further analysis indicated that there were strong correlations between $V D P$ and the survival environments of the vegetation in the basins, as well as strong correlations between $V R P$ and pre-earthquake vegetation survival environment. These relationships can be expressed by

$$
\begin{gathered}
V D P=\eta \sin (S)+\varphi V+\lambda\left(1-R_{h}+D\left|\sin \left(\frac{A}{2}+\frac{\pi}{4}\right)\right|, \quad l=i\right. \\
V R P=\tau V+\varepsilon\left[D+\cos (S)+R_{h} \mid \sin \left(\frac{A}{2}-\frac{\pi}{4}\right)\right], \quad l=i
\end{gathered}
$$

where $V D P$ is the vegetation damaged probability in each of the DHSAL regions, and $\eta, \varphi, \lambda$, and $i$ are the parameters of function (Table 2). $V R P$ is the vegetation recovered probability in each of the DHSAL regions, and $\tau, \varepsilon$, and $i$ are parameters of function (Table 3), also calculated using the stepwise multiple regression method. 
Table 2. Parameters of Equation (2) in river basins.

\begin{tabular}{cccccc}
\hline River basin & $\eta$ & $\varphi$ & $\lambda$ & $\boldsymbol{i}$ & $\boldsymbol{R}^{2}$ \\
\hline Baisha & 0.676 & -0.545 & 0.273 & 1 & 0.813 \\
Baisha & 0.561 & -0.457 & 0.244 & 2 & 0.754 \\
Longxi & 0.613 & -0.326 & 0.159 & 1 & 0.805 \\
Longxi & 0.754 & -0.556 & 0.250 & 2 & 0.726 \\
\hline
\end{tabular}

Table 3. Parameters of Equation (3) in river basins.

\begin{tabular}{ccccc}
\hline River basin & $\tau$ & $\varepsilon$ & $\boldsymbol{i}$ & $\boldsymbol{R}^{\mathbf{2}}$ \\
\hline Baisha & 1.831 & -0.189 & 1 & 0.874 \\
Baisha & 1.713 & -0.231 & 2 & 0.835 \\
Longxi & 1.988 & -0.343 & 1 & 0.854 \\
Longxi & 1.295 & -0.132 & 2 & 0.792 \\
\hline
\end{tabular}

\section{Modeling Sediment and Flow Connectivity in One Given Basin}

\subsection{Modeling the Slope Material Stability}

Surface materials make up the bulk of landslides, and landslide processes are largely determined by the slope gradient, slope materials, elevation, and hydrological conditions. All these causative factors influence the vegetation growth and vegetation survival environment. Thus, there are some coupling relationships between landslide processes and vegetation growth, and spatial analysis of landslide-damaged vegetation is important for understanding which terrain and surface materials are susceptible to landslide processes. Although there is not yet a complete understanding of the interaction of vegetation and landslide processes, these coupling relationships can be confirmed by the use of statistical analyses or other methods.

The reduction of shear strength and overall soil cohesion, combined with ground acceleration from seismic waves, was responsible for the failure of many shallow slopes in the Wenchuan earthquake region [35]. In essence, the earthquake-induced geo-hazards are strongly controlled by three important factors: i.e., topographical conditions, slope materials properties, and ground shaking. Since it is a complex process when an earthquake produces a range of ground shaking levels at sites throughout the region, the ground-shaking condition is more difficult to handle in modeling practice. However, the earthquake-induced geo-hazards were strongly correlated with elevation, slope gradient, slope aspect, geological units, and hydrological conditions at the basin scale.

Our spatial distribution analysis of the pre-earthquake vegetation, earthquake-damaged vegetation, and post-earthquake recovery processes indicated that vegetation growth is influenced by survival environments (i.e., topographical conditions and materials properties), and the damaged vegetation conditions during earthquakes were strongly influenced by elevation, slope gradient, slope aspect, geological units, hydrological conditions and vegetation characteristics of the slope. Further, post-earthquake recovery processes also have direct relationships with the survival environment. All these results show that the spatial analysis of earthquake vegetation can provide useful information regarding the susceptibility of particular terrain and surface materials to landslide processes and that the historical earthquake-damaged vegetation data can be used to predict future slope stability. Here, 
the $V D P$ was used as one parameter to represent the slope materials' stability at the basin scale, and the susceptibility index $P$ of slope materials stability can be calculated according to:

$$
P=\eta \sin (s)+\varphi v+\lambda\left(1-r_{h}+d\left|\sin \left(\frac{a}{2}+\frac{\pi}{4}\right)\right|\right), \quad l=i
$$

where $P$ is the slope materials stability susceptibility index, $\eta, \varphi, \lambda$, and $i$ are the parameters of the function (Table 2), $s$ is the slope gradient, $v$ is the NDVI value, $r_{h}$ is the ratio of the $H_{d}$ value to the maximum $H_{d}$ value of the basin, $d$ is the ratio of the height of the contour above the base (basin mouth) to the total height of the basin, and $a$ is the slope aspect. The model provides a time-varying estimate of the surface material stability by linking vegetation growth data with spatially varying topographical environment and material properties.

\subsection{Sediment and Flow Connectivity Index, SCFI}

Mass-wasting processes in mountainous terrain are the primary ways in which landscapes evolve, and are not only dependent on the sediment source conditions but also on the spatial organization and internal connectivity of various parts of a catchment [36-38]. Knowledge of the spatial distribution and temporal evolution of connectivity in the given catchment is important because they can be used to estimate the sediment and flow transfer of a specific area and its contribution elsewhere in the catchment [37]. In addition, vegetation plays an important role because it influences surface roughness and local capacity to store sediment and water. Importantly, the above-ground biomass of vegetation changes the surface material (sediment) hydrology extensively through evaporation and transpiration processes [39-41], and vegetation affects the mechanical and hydrological properties of sediment through the effects of developing root systems. Thus, vegetation contributes to the sediment and flow connectivity of upstream and downstream areas.

In the Wenchuan earthquake-hit region, the earthquake-induced landslides destroyed large areas of vegetation, which made the vegetation hydrological adjusting function diminish. Hence, large amounts of unconsolidated materials deposited on the steep slopes, which changed the hydrological processes (i.e., infiltration reduced, run-off increased and flow concentration expedited ) in the catchment [6]. Existing research indicates that the combination of steep slope, abundant fragmented materials, and high intensity rainfall naturally leads to the catastrophic debris flows in the earthquake-hit area [2,42-44].

Spatial analysis of the sediment and flow connectivity of a specific area (point) in the river basins allowed estimation of the contribution of the upslope areas as the sediment and flow source, and can be used to assess the transport progress (i.e., transport path and capacity) of the downslope areas. Since the sediment and flow connectivity of a given point in the catchment depends on its actual conditions (i.e., size, slope gradient, relief, and sediment properties) of upslope area and the transport pathway (i.e., initial elevation, flow length, and sediment supply conditions) of the downslope area, we defined one sediment and flow connectivity index $(S F C I)$, which included the upslope $\left(S F_{u p}\right)$ and downslope $\left(S F_{d n}\right)$ components, to quantify the spatial connectivity of sediment and flow in the mountain basins. The $S F C I$ model can be expressed by

$$
S F C I=\ln \left(\frac{S F_{u p}}{S F_{d n}}\right)
$$




$$
\begin{gathered}
S F_{u p}=\bar{P} A \bar{H} \sin (\bar{S}) \\
S F_{d n}=\frac{V_{d}}{H_{d}} \sum_{i}\left(1-P_{i}\right) R_{i},
\end{gathered}
$$

where $\bar{P}$ is the mean $P$ value of the upslope area which is used to describe the sediment properties, $A$ is the size of the upslope area $\left(\mathrm{m}^{2}\right), \bar{H}$ is the mean relative relief of the upslope area $(\mathrm{m}), \bar{S}$ is the mean slope gradient of the upslope area $(\mathrm{m})$, and $R_{i}$ is the cell size of the given point.

\section{Results}

\subsection{Slope Material Stability Changes in Study Area}

The earthquake-damaged vegetation during the Wenchuan earthquake was used in the model (Equation (4)) to describe the relations between the slope material stability with its topographical environments and geological and vegetative conditions. Then, three slope materials stability maps of the Baisha River and Longxi River basins were calculated as shown in Figure 7.

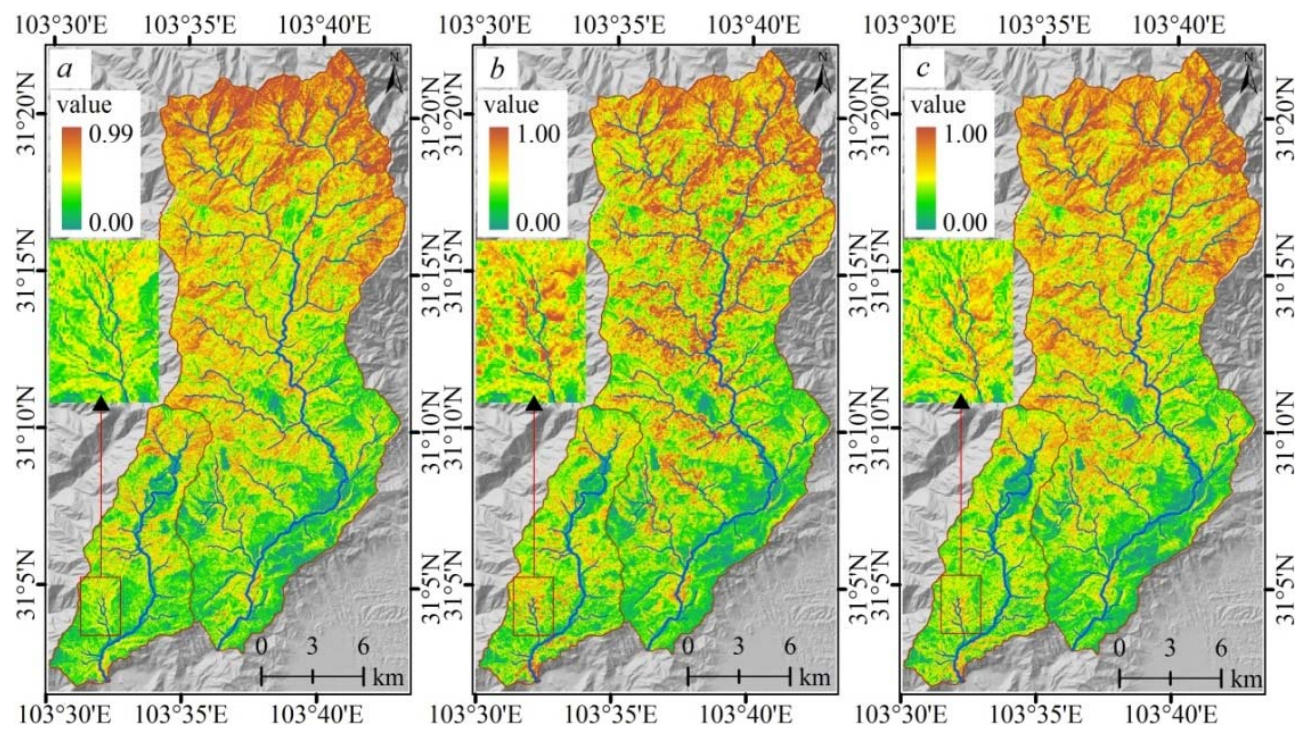

Figure 7. (a) Pre-earthquake; (b) 2008-2009; and (c) 2014 slope materials stability maps of the study area.

Figure 7 shows the changing processes of the slope material stability as found by monitoring the vegetation changes before and after the earthquake. The results indicated that high susceptibility areas were zonally distributed along the steep slopes of the stream channels and the bare areas of the mountain top (Figure 7a), the susceptibility of these vegetation-damaged areas had an obvious increase after the earthquake (Figure $7 \mathrm{~b}$ ), and the slope material stability in these damaged areas showed some improvement with the vegetation recovery a few years after the earthquake (Figure 7c).

The statistical results showed that there are about $205 \mathrm{~km}^{2}$ areas with $P>0.35$ before the earthquake, which accounted for $48.1 \%$ of the total area, and there were about $86.7 \mathrm{~km}^{2}$ vegetation-damaged areas (Figure $8 \mathrm{a}$ ) with $P>0.35$ (71.1\% of the total vegetation-damaged area), while there were $191 \mathrm{~km}^{2}$ areas with $H_{d}<500 \mathrm{~m}$, which accounted for $44.0 \%$ of the total area, and there are about $68.7 \mathrm{~km}^{2}$ 
vegetation-damaged areas (Figure $8 \mathrm{~b})$ with $H_{d}<500 \mathrm{~m}(56.3 \%$ of the total vegetation-damaged area). Hence, the areas with $H_{d}<500 \mathrm{~m}$ are susceptible to slope failures.
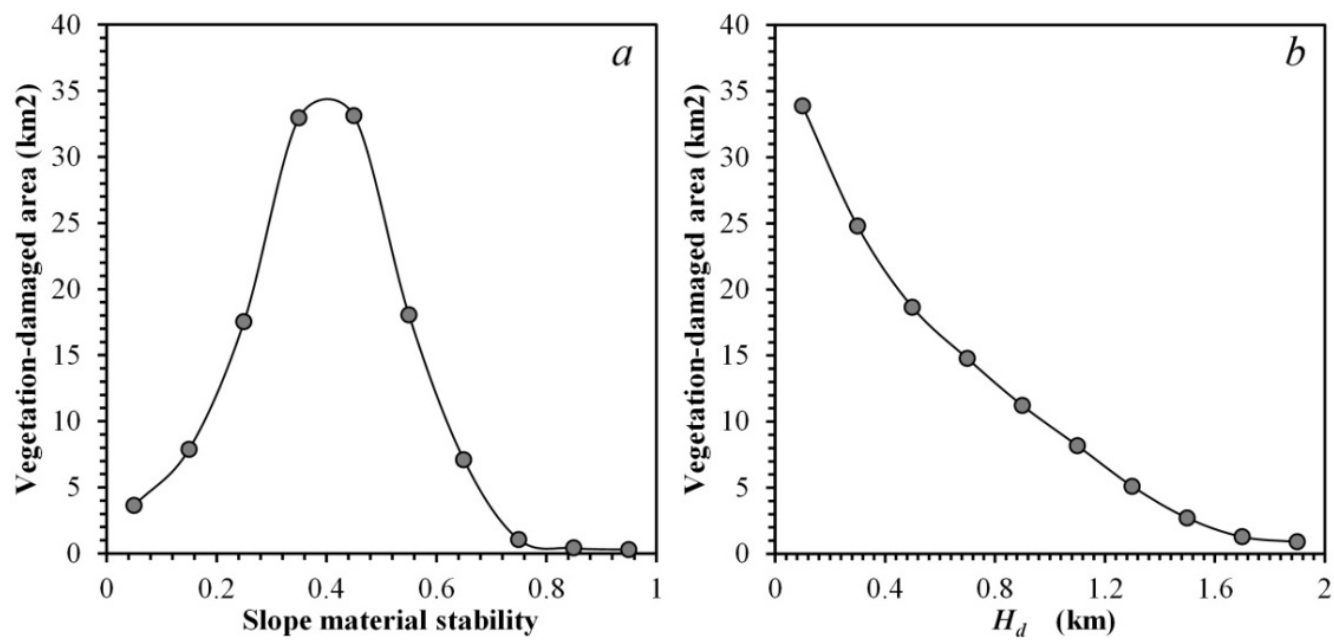

Figure 8. Vegetation-damaged distributions with the slope material stability (a) and after the horizontal distance to river streams, $H_{d}(\mathbf{b})$.

\subsection{SFCI Changes in Study Area}

Based on the three slope material stability maps, we calculated the SFCI maps of the Baisha River and Longxi River to detect the SFCI changes before and after the earthquake (Figure 9). The results showed that the areas with $H_{d}<500 \mathrm{~m}$ had high $S F C I$ values before the earthquake (Figure 9a), the $S F C I$ values of these areas had obvious increases after the earthquake (Figure 9b), and the areas with obvious $S F C I$ increased had some decreases in vegetation recovery (Figure 9c).

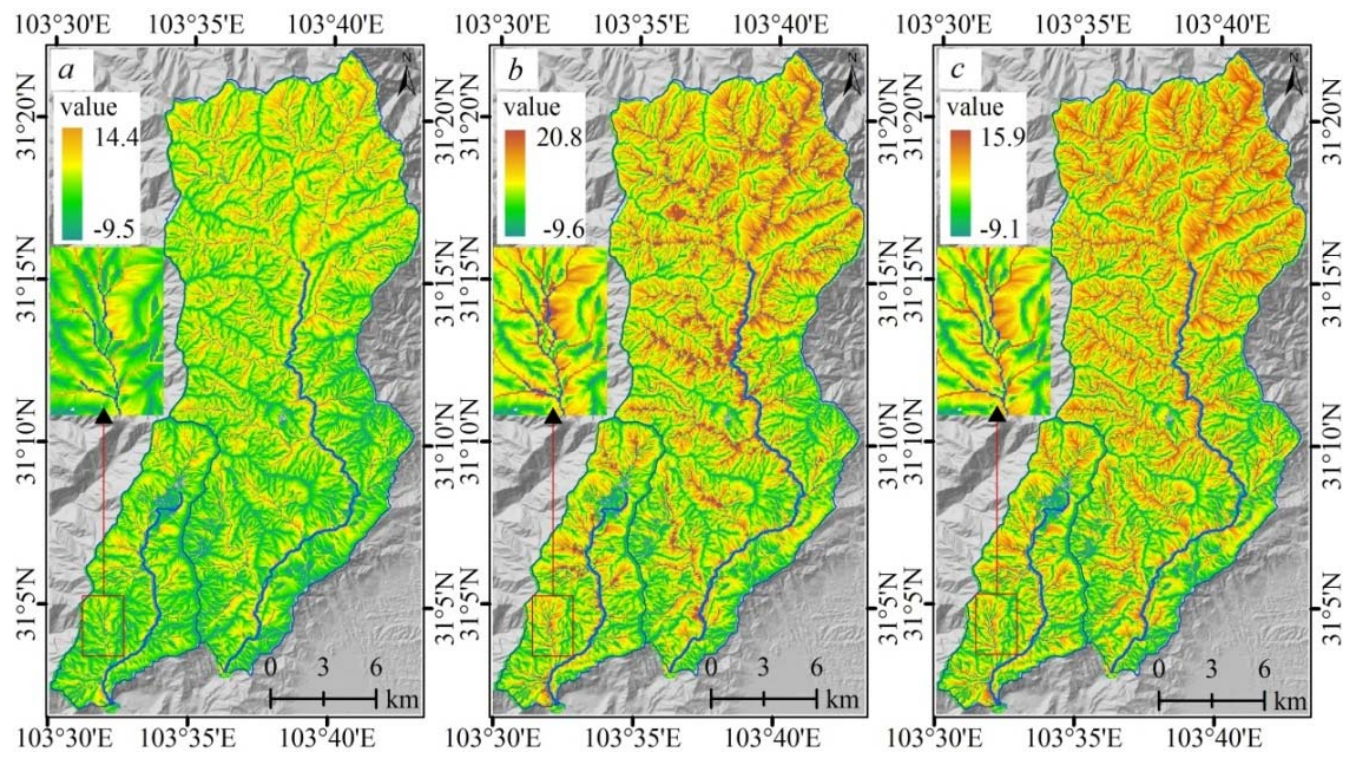

Figure 9. (a) Pre-earthquake SFCI map of the study area; (b) 2008-2009 SFCI map of the study area; (c) 2014 SFCI map of the study area. 
The statistical results (Figure 10) show that the SFCI values of both the Baisha and Longxi River showed some increase after the earthquake, especially in areas with $H_{d}<500 \mathrm{~m}$ (average of 1.60 increases in Baisha River and 1.50 increases in Longxi River), and the SFCI values showed an obvious decrease in the areas with $H_{d}<500 \mathrm{~m}$ a few years after the earthquake. The areas with $H_{d}>500 \mathrm{~m} \mathrm{had}$ small changes after a few years after the earthquake, although the earthquake-damaged vegetation reduced the slope material stability and increased the mass-wasting processes.
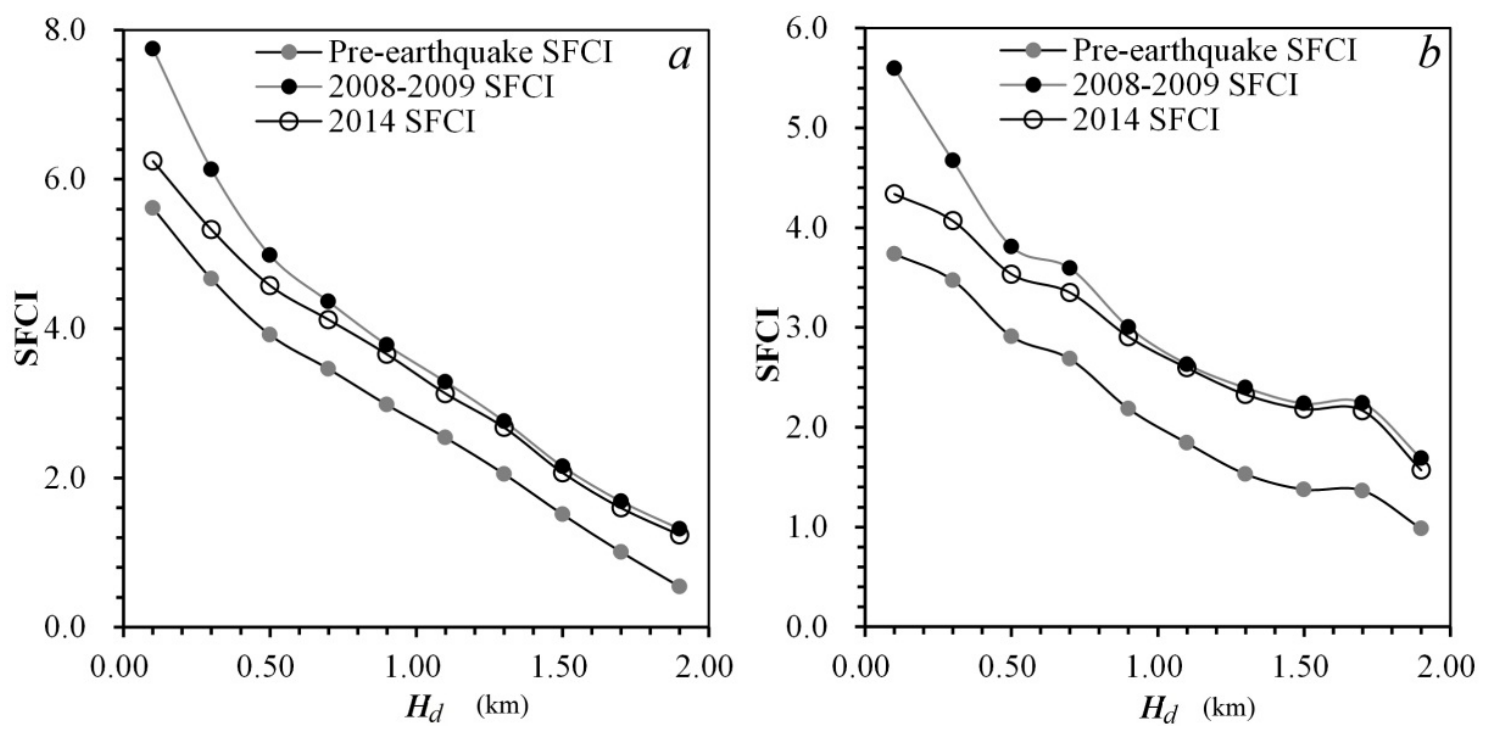

Figure 10. SFCI change processes before and after the earthquake (pre-earthquake, 2008-2009, and 2014) within the Baisha River basin (a) and the Longxi River basin (b).

After the 2008 earthquake, both the Baisha River and Longxi River suffered several debris flow events, especially from 13 to 14 August 2010, when one heavy rainstorm triggered one seriously catastrophic debris flow event in these river basins, and about 34 gully-type debris flows were triggered in the Longxi River [45]. In addition, existing studies indicate that the triggering rainfall threshold for debris flow significantly decreased after the earthquake, and the lowest rainfall intensity and rainfall amount for debris flow increased annually with the slope material stability enhancement and damaged vegetation recovery [42,46-48].

Considering the SFCI changes in both the Baisha River and Longxi River, the spatial results indicated that the areas with $H_{d}<500 \mathrm{~m}$ are susceptible to the mass wasting processes in mountainous rivers, and we consider that these specific areas actively contribute sediment to the stream channel network.

\section{Discussion}

\subsection{Relationships between Vegetation and Slope Stability}

Vegetation can root through thin slope material into the underlying bedrock and provide considerable strength to materials on sloping land, and most slope materials influence vegetation growth and impact the vegetation survival environment. In addition, vegetation can impact the hydrological processes along the slope. Hence, there is some relationship between the slope stability 
and vegetation, although there is no complete understanding of the interaction between vegetation and slope material.

Our spatial results demonstrated that the vegetation growth, earthquake-damaged vegetation, and its recovery processes had strong relationships with the topographical and slope material properties. Slope material stability is mainly controlled by the topographical conditions and material properties, and the damaged vegetation is mainly caused by the slope failures during the earthquake. Hence, spatial analysis of the damaged vegetation and its recovery processes is important for understanding what terrain and materials are susceptible to slope failures (or landslide processes). In addition, the recovery of these Wenchuan earthquake-damaged vegetation areas are generally long-term biological process; therefore, it is important to monitor regional vegetation dynamics.

\subsection{Debris Flow Events in Longxi River}

The identification of specific areas that actively contribute sediment to the stream channel network is a necesSARy prerequisite for understanding the sediment delivery process and developing successful sediment management programs [36]. We modeled the SFCI to find the areas with obvious SFCI increases in the Longxi River (Figure 11a) and found that there were many debris flow events after the earthquake (2008-2010) around the areas with obvious SFCI increases (Figure 11b). Currently, these areas showed some SFCI decreases with the vegetation recovery processes (Figure 11c). In addition, some existing studies have found that the lowest rainfall intensity and rainfall amount for debris flow initiation increased annually in the Wenchuan earthquake-hit region [48]. Hence, we consider that the SFCI model can detect and monitor the specific areas that actively contribute sediment to masswasting processes in the mountainous river basin.

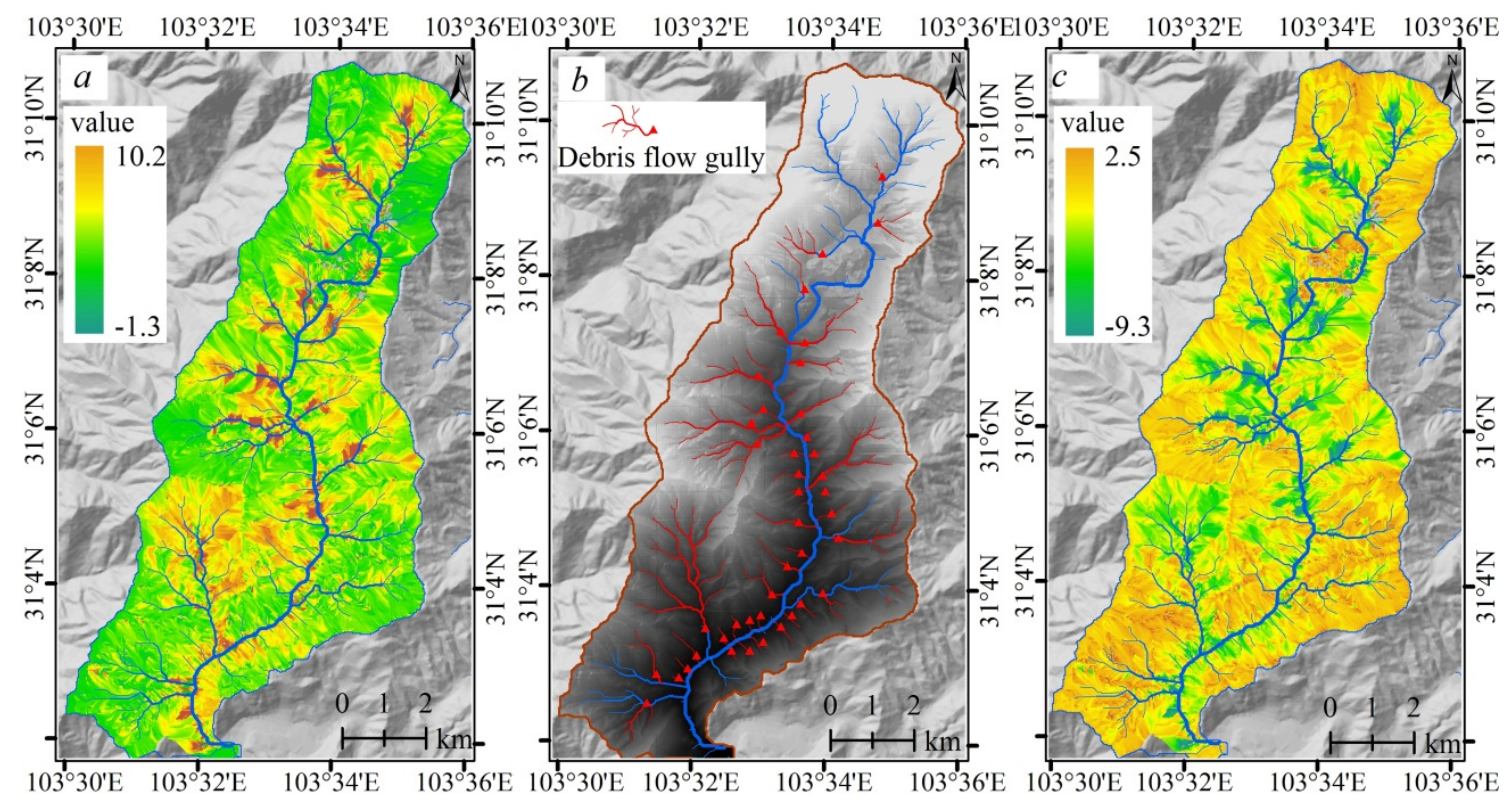

Figure 11. (a) $S F C I$ increase map after the earthquake; (b) post-earthquake debris flow events; (c) SFCI decrease map a few years after the earthquake at the Longxi River. 


\subsection{Validity of the Sediment and Flow Connectivity Model}

This sediment and flow connectivity model was based on the slope material stability model, which was trained using the earthquake-damaged vegetation data in mountainous basins of the Wenchuan earthquake-affected region. Hence, the SFCI is strongly influenced by the quality of the (existing) damaged vegetation data. In other regions, this model requires sufficient damaged vegetation data to detect the hydrological process changes in a given mountainous basin.

In addition, this model index was influenced by the DEM resolution, which controls the quality of the topographical (slope gradient and aspect) and hydrological (flow direction and accumulation) calculations. However, this is a common question for most hydrological analysis. Using the DEM data with different resolution, there may be some obvious errors in the model calculation. Hence, suitable DEM data should be chosen for different applications to reduce errors.

\section{Conclusions}

In this study, we presented a probabilistic approach for slope material stability analysis that quantitatively relates the earthquake-damaged vegetation data with topographical and material properties in a given river basin. We modeled sediment and flow connectivity to detect the hydrological process changes after the earthquake by monitoring the vegetation dynamics. Our results demonstrated that the areas with $H_{d}<500 \mathrm{~m}$ actively contribute sediment to the stream channel network, and these areas are the main sources for debris flow processes in the Longxi River and Baisha River, in the Wenchuan earthquake-hit region.

Since damaged vegetation recovery is generally a long-term biological process, it is important to monitor regional vegetation dynamics (vegetation recovery processes) and determine how ecological status and trends have changed after the earthquake. The spatial analysis of the earthquake-damaged vegetation and its recovery processes is very important for understanding what terrain and surface materials are susceptible to slope failures (or debris flow processes).

\section{Acknowledgments}

This research was financially supported by the National Science and Technology Support Program (2012BAC06B02) and Key Projects of the Chinese Academy of Sciences (KZZD-EW-05-01-04). The Landsat-5/7/8 images were provided by the Open Spatial Data Sharing System of Institute of Remote Sensing and Digital Earth, Chinese Academy of Sciences (www.ids.ceode.ac.cn).

\section{Author Contributions}

The analysis was performed by Huaizhen Zhang, Xiaomeng Wang, and Shun Yang. Jianrong Fan, Tianhe Chi, and Ling Peng contributed concepts and participated in discussions and writing the manuscript. All authors read and approved the final manuscript.

\section{Conflicts of Interest}

The authors declare no conflict of interest. 


\section{References}

1. Huang, R.; Li, W. Development and distribution of geohazards triggered by the 5.12 Wenchuan earthquake in China. Sci. China Series E: Technol. Sci. 2009, 52, 810-819.

2. Cui, P.; Chen, X.; Zhu, Y.; Su, F.; Wei, F.; Han, Y.; Liu, H.; Zhuang, J. The Wenchuan earthquake (may 12, 2008), Sichuan Province, China, and resulting geohazards. Nat. Hazards 2009, 56, 19-36.

3. Dai, F.C.; Xu, C.; Yao, X.; Xu, L.; Tu, X.B.; Gong, Q.M. Spatial distribution of landslides triggered by the $2008 \mathrm{Ms} 8.0$ Wenchuan earthquake, China. J. Asian Earth Sci. 2011, 40, 883-895.

4. Qi, S.; Xu, Q.; Lan, H.; Zhang, B.; Liu, J. Spatial distribution analysis of landslides triggered by 2008.5.12 Wenchuan earthquake, China. Eng. Geol. 2010, 116, 95-108.

5. Xu, C.; Xu, X.; Yao, X.; Dai, F. Three (nearly) complete inventories of landslides triggered by the may 12, 2008 Wenchuan Mw 7.9 earthquake of China and their spatial distribution statistical analysis. Landslides 2013, 11, 441-461.

6. Cui, P.; Lin, Y.; Chen, C. Destruction of vegetation due to geo-hazards and its environmental impacts in the Wenchuan earthquake areas. Ecol. Eng. 2012, 44, 61-69.

7. Tang, C.; Zhu, J.; Qi, X.; Ding, J. Landslides induced by the Wenchuan earthquake and the subsequent strong rainfall event: A case study in the beichuan area of China. Eng. Geol. 2011, $122,22-33$.

8. Zhang, S.; Zhang, L.M.; Glade, T. Characteristics of earthquake- and rain-induced landslides near the epicenter of Wenchuan earthquake. Eng. Geol. 2014, 175, 58-73.

9. Wu, Z.; Barosh, P.J.; Zhang, Z.; Liao, H. Effects from the Wenchuan earthquake and seismic hazard in the Longmenshan Mountains at the eastern margin of the Tibetan Plateau. Eng. Geol. 2012, 143-144, 28-36.

10. Liu, G.; Li, J.; Xu, Z.; Wu, J.; Chen, Q.; Zhang, H.; Zhang, R.; Jia, H.; Luo, X. Surface deformation associated with the 2008 Ms8.0 Wenchuan earthquake from ALOS 1-band SAR interferometry. Int. J. Appl. Earth Obs. Geoinform. 2010, 12, 496-505.

11. Chen, F.; Guo, H.; Ishwaran, N.; Zhou, W.; Yang, R.; Jing, L.; Chen, F.; Zeng, H. Synthetic aperture radar (SAR) interferometry for assessing Wenchuan earthquake (2008) deforestation in the Sichuan giant panda site. Remote Sens. 2014, 6, 6283-6299.

12. Liu, Y.; Liu, R.; Ge, Q. Evaluating the vegetation destruction and recovery of Wenchuan earthquake using modis data. Nat. Hazards 2010, 54, 851-862.

13. Lu, T.; Zeng, H.; Luo, Y.; Wang, Q.; Shi, F.; Sun, G.; Wu, Y.; Wu, N. Monitoring vegetation recovery after China's may 2008 Wenchuan earthquake using Landsat TM time-series data: A case study in Mao County. Ecol. Res. 2012, 27, 955-966.

14. Jiao, Q.; Zhang, B.; Liu, L.; Li, Z.; Yue, Y.; Hu, Y. Assessment of spatio-temporal variations in vegetation recovery after the Wenchuan earthquake using Landsat data. Nat. Hazards 2014, 70, 1309-1326.

15. Zhang, J.; Hull, V.; Huang, J.; Yang, W.; Zhou, S.; Xu, W.; Huang, Y.; Ouyang, Z.; Zhang, H.; Liu, J. Natural recovery and restoration in giant panda habitat after the Wenchuan earthquake. For. Ecol. Manag. 2014, 319, 1-9. 
16. Li, Z.; Jiao, Q.; Liu, L.; Tang, H.; Liu, T. Monitoring geologic hazards and vegetation recovery in the Wenchuan earthquake region using aerial photography. ISPRS Int. J. Geo-Inform. 2014, 3, 368-390.

17. Lin, W.-T.; Chou, W.-C.; Lin, C.-Y.; Huang, P.-H.; Tsai, J.-S. Vegetation recovery monitoring and assessment at landslides caused by earthquake in central taiwan. For. Ecol. Manag. 2005, 210, 55-66.

18. Garwood, N.C. Earthquake-caused landslides in panama: Recovery of the vegetation. Natl. Geogr. Soc. Res. Rep. (USA) 1985, 21, 182-183.

19. Lin, W.-T.; Chou, W.-C.; Lin, C.-Y. Earthquake-induced landslide hazard and vegetation recovery assessment using remotely sensed data and a neural network-based classifier: A case study in central taiwan. Nat. Hazards 2008, 47, 331-347.

20. Koi, T.; Hotta, N.; Ishigaki, I.; Matuzaki, N.; Uchiyama, Y.; Suzuki, M. Prolonged impact of earthquake-induced landslides on sediment yield in a mountain watershed: The Tanzawa Region, japan. Geomorphology 2008, 101, 692-702.

21. Lin, W.-T.; Lin, C.-Y.; Chou, W.-C. Assessment of vegetation recovery and soil erosion at landslides caused by a catastrophic earthquake: A case study in Central Taiwan. Ecol. Eng. 2006, 28, 79-89.

22. Rau, J.-Y.; Chen, L.-C.; Liu, J.-K.; Wu, T.-H. Dynamics monitoring and disaster assessment for watershed management using time-series satellite images. IEEE Trans. Geosci. Remote Sens. 2007, 45, 1641-1649.

23. Yeh, C.-H.; Loh, C.-H.; Tsai, K.-C. Overview of Taiwan earthquake loss estimation system. Nat. Hazards 2006, 37, 23-37.

24. Stow, D.A.; Hope, A.; McGuire, D.; Verbyla, D.; Gamon, J.; Huemmrich, F.; Houston, S.; Racine, C.; Sturm, M.; Tape, K.; et al. Remote sensing of vegetation and land-cover change in arctic tundra ecosystems. Remote Sens. Environ. 2004, 89, 281-308.

25. Stern, M.J.; Churchill, S.; Balslev, H.; Forero, E.; Luteyn, J. Vegetation recovery on earthquake-triggered landslide sites in the Ecuadorian Andes. In Proceedings of a Symposium Biodiversity and Conservation of Neotropical montane Forests, New York Botanical Garden, NY, USA, 21-26 June 1995; pp. 207-220.

26. Nakashizuka, T.; Iida, S.; Suzuki, W.; Tanimoto, T. Seed dispersal and vegetation development on a debris avalanche on the Ontake Volcano, Central Japan. J. Veg. Sci. 1993, 4, 537-542.

27. Lin, C.-Y.; Lo, H.-M.; Chou, W.-C.; Lin, W.-T. Vegetation recovery assessment at the Jou-Jou Mountain landslide area caused by the 921 earthquake in Central Taiwan. Ecol. Modell. 2004, $176,75-81$.

28. Chou, W.-C.; Lin, W.-T.; Lin, C.-Y. Vegetation recovery patterns assessment at landslides caused by catastrophic earthquake: A case study in Central Taiwan. Environ. Monit. Assess. 2009, 152, $245-257$.

29. Shieh, C.L.; Chen, Y.S.; Tsai, Y.J.; Wu, J.H. Variability in rainfall threshold for debris flow after the Chi-Chi earthquake in Central Taiwan, China. Int. J. Sediment Res. 2009, 24, 177-188. 
30. Chu, H.-J. Spatiotemporal analysis of vegetation index after typhoons in the mountainous watershed. Int. J. Appl. Earth Obs. Geoinform. 2014, 28, 20-27.

31. Tofani, V.; Del Ventisette, C.; Moretti, S.; Casagli, N. Integration of remote sensing techniques for intensity zonation within a landslide area: A case study in the Northern Apennines, Italy. Remote Sens. 2014, 6, 907-924.

32. Qiao, G.; Lu, P.; Scaioni, M.; Xu, S.; Tong, X.; Feng, T.; Wu, H.; Chen, W.; Tian, Y.; Wang, W.; et al. Landslide investigation with remote sensing and sensor network: From susceptibility mapping and scaled-down simulation towards in situ sensor network design. Remote Sens. 2013, $5,4319-4346$.

33. Bathurst, J.C.; Bovolo, C.I.; Cisneros, F. Modelling the effect of forest cover on shallow landslides at the river basin scale. Ecol. Eng. 2010, 36, 317-327.

34. Zhang, H.; Chi, T.; Fan, J.; Hu, K.; Peng, L. Spatial analysis of Wenchuan earthquake-damaged vegetation in the mountainous basins and its applications. Remote Sens. 2015, 7, 5785-5804.

35. Yang, X.; Chen, L. Using multi-temporal remote sensor imagery to detect earthquake-triggered landslides. Int. J. Appl. Earth Obs. Geoinform. 2010, 12, 487-495.

36. Croke, J.; Mockler, S.; Fogarty, P.; Takken, I. Sediment concentration changes in runoff pathways from a forest road network and the resultant spatial pattern of catchment connectivity. Geomorphology 2005, 68, 257-268.

37. Borselli, L.; Cassi, P.; Torri, D. Prolegomena to sediment and flow connectivity in the landscape: A GIS and field numerical assessment. Catena 2008, 75, 268-277.

38. Hooke, J. Coarse sediment connectivity in river channel systems: A conceptual framework and methodology. Geomorphology 2003, 56, 79-94.

39. Haneberg, W.C. Observation and analysis of pore pressure fluctuations in a thin colluvium landslide complex near cincinnati, Ohio. Eng. Geol. 1991, 31, 159-184.

40. Marston, R.A. Geomorphology and vegetation on hillslopes: Interactions, dependencies, and feedback loops. Geomorphology 2010, 116, 206-217.

41. Harden, C.P. Human impacts on headwater fluvial systems in the northern and central Andes. Geomorphology 2006, 79, 249-263.

42. Tang, C.; Zhu, J.; Li, W.L.; Liang, J.T. Rainfall-triggered debris flows following the Wenchuan earthquake. Bull. Eng. Geol. Environ. 2009, 68, 187-194.

43. Tang, C.; Zhu, J.; Ding, J.; Cui, X.F.; Chen, L.; Zhang, J.S. Catastrophic debris flows triggered by a 14 August 2010 rainfall at the epicenter of the Wenchuan earthquake. Landslides 2011, 8, 485-497.

44. Xu, Q.; Zhang, S.; Li, W.L.; van Asch, T.W.J. The 13 August 2010 catastrophic debris flows after the 2008 Wenchuan earthquake, China. Nat. Hazards Earth Syst. Sci. 2012, 12, 201-216.

45. Li, L.; Yu, B.; Zhu, Y.; Chu, S.; Wu, Y. Topographical factors in the formation of gully-type debris flows in Longxi River Catchment, Sichuan, China. Environ. Earth Sci. 2014, doi:10.1007/s12665-12014-13722-12667.

46. Cui, P.; Hu, K.; Zhuang, J.; Yang, Y.; Zhang, J. Prediction of debris-flow danger area by combining hydrological and inundation simulation methods. J. Mt. Sci. 2011, 8, 1-9.

47. Cui, P.; Zhou, G.G.D.; Zhu, X.H.; Zhang, J.Q. Scale amplification of natural debris flows caused by cascading landslide dam failures. Geomorphology 2013, 182, 173-189. 
48. Guo, X.; Cui, P.; Ma, L.; Kong, Y. Triggering rainfall characteristics for debris flows along Dujiangyan-Wenchuan Highway of Sichuan Mount. Res. 2014, 6, 736-346.

(C) 2015 by the authors; licensee MDPI, Basel, Switzerland. This article is an open access article distributed under the terms and conditions of the Creative Commons Attribution license (http://creativecommons.org/licenses/by/4.0/). 